\title{
Preliminary results of indoor moisture excess measurements for residential and office buildings in Latvia
}

\author{
Jurgis Zemitis ${ }^{1, *}$ and Raimonds Bogdanovics ${ }^{1}$ \\ ${ }^{1}$ Riga Technical University, Institute of Heat, Gas and Water Technology; Kipsalas street 6A, LV-1048, Riga, Latvia
}

\begin{abstract}
It is vitally important to understand the moisture transfer process in the buildings as this knowledge allows to generate solutions on how to control it. The data about typical indoor air humidity levels and moisture sources are usually taken from the existing standards. However, this information needs to be verified and adapted for the local situation as occupant behaviour varies for each country. Similar studies have been performed in Estonia and Finland and they indicate that the typical data of these northern countries differ from the one provided in the standard. This paper presents the preliminary results of moisture measurements for several residential and office buildings in Latvia. Afterward, the difference between indoor and outdoor air absolute humidity is calculated and the data is analyzed depending on the outside air temperature. The results can be used to provide suggestions on the adaption of EN ISO 13788:2012 Figure A.2 which presents the information on the variation of internal humidity classes with external temperatures. The study is not yet completed as more measurements must be taken since the outside temperatures have dropped under zero degrees only for a few days and the number of the test objects must be increased.
\end{abstract}

\section{Introduction}

Understanding and considering the moisture production and transfer process in the residential and office buildings is still one of the most important design phases. However, due to the moisture source variety and uncertainty as well as the complexity of calculations caused by different affecting forces moisture control is often neglected. This can cause various problems such as condensation on the internal surfaces or mould growth [1] and can lead to various health problems like asthma and allergies as they are directly linked to building dampness [2], [3].

As the building stock is still dominated by the old Soviet time buildings which were not equipped with mechanical ventilation, moisture is often a significant problem. It is especially important in cases when the windows are changed or the building is renovated, as this further reduces the natural ventilation and therefore rises the indoor moisture levels.

To perform moisture calculations the standard EN ISO 13788:2013 [4] is often used. The standard gives information on moisture difference between indoors and outdoors depending on the outdoor temperature classifying it based on building type. Five standard humidity classes are defined to be used as design values in hygrothermal calculations. For dwellings, two classes are applied depending on house occupancy: class $3: \Delta \mathrm{v}=4-6 \mathrm{~g} / \mathrm{m}^{3}$ for low occupancy and class $4: \Delta \mathrm{v}=6-8 \mathrm{~g} / \mathrm{m}^{3}$ for high occupancy, when the outdoor temperature is $<0^{\circ} \mathrm{C}$. This standard also suggests using a safety margin 1.1 when the steady-state calculation method is used. The graph shows that the internal moisture excess is constant for monthly mean outdoor temperatures $\leq 0{ }^{\circ} \mathrm{C}$ and decreases linearly to $1 \mathrm{~g} / \mathrm{m}^{3}$ at monthly mean outdoor temperatures of $+20^{\circ} \mathrm{C}$, see Fig. 1 .

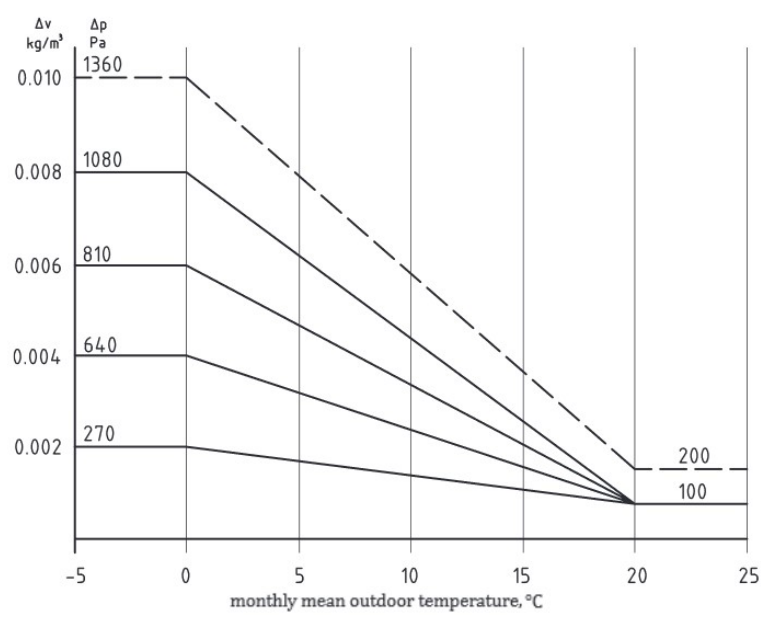

Fig. 1. Variation of internal humidity classes with external temperature [4]

However, in the standard, it is stated that the data are derived from measurements performed in Western European buildings. This means that it should be adapted for the local conditions of Northern Europe. Such studies have already been performed in Estonia and Finland and

*Corresponding author: jurgis.zemitis@rtu.lv 
they indicate that the typical data of these northern countries differ from the one provided in the standard. According to existing researches, the critical points of the moisture supply are not $+20^{\circ} \mathrm{C}$ and $0^{\circ} \mathrm{C}$, but $\approx+15^{\circ} \mathrm{C}$ and $\approx+5^{\circ} \mathrm{C}$, moreover, the internal moisture supply is not completely constant at the temperature $\leq+5^{\circ} \mathrm{C}$ and is positive at temperatures above $+20^{\circ} \mathrm{C}$ [5], [6]. Longterm measurements in buildings to determine humidity and temperature have also been performed in the USA [7], China [8], Norway [9], Sweden [10], etc.

To determine the moisture difference, it is necessary to calculate the internal moisture production. It can be a challenging task as there are a lot of moisture sources and they are changing during the day and week. For example, research [11] summarized information from different literature sources about typical moisture production rates and found that 1 person produces at least $0.9 \mathrm{~kg} / \mathrm{d}$, during hard work this value can increase even till $7.2 \mathrm{~kg} / \mathrm{d}$. More moisture can be produced by cooking $(0.8-3 \mathrm{~kg} / \mathrm{d})$, sauna $(1.28 \mathrm{~kg} / \mathrm{h})$ or drying clothes $(0.05-3.5 \mathrm{~kg} / \mathrm{d})$. By considering weekly average moisture supply, ventilation air change rate and house occupancy, Kalamees [12] found, that in the winter season, the average daily moisture production in the studied houses in Finland was $5.9 \mathrm{~kg} / \mathrm{day} / \mathrm{house}$ $(1.9 \mathrm{~kg} /$ day/person), in Estonia $5.4 \mathrm{~kg} /$ day/house $(1.6 \mathrm{~kg} /$ day $/$ person $)$. An average value from the daily maximum moisture production values in Finland was $12.7 \mathrm{~kg} /$ day/house $\quad(4.0 \mathrm{~kg} /$ day/person $)$, in Estonia $13.0 \mathrm{~kg} /$ day/house $(4.1 \mathrm{~kg} /$ day/person $)$. The maximum value of daily moisture production during one week in Finland was $18.6 \mathrm{~kg} /$ day/house $(7.5 \mathrm{~kg} /$ day/person). According to measurements [13] in historic wooden apartment buildings in Estonia, the average moisture production in the bedrooms during the night was $60 \mathrm{~g} / \mathrm{h}$ $(1.44 \mathrm{~kg} / \mathrm{d})$ with variation between 14 and $200 \mathrm{~g} / \mathrm{h}$. According to [14] the moisture production due to cloth drying is around $1067 \mathrm{~g} /$ day for 4 person household.

Potentially the number of occupants can also have an effect on the moisture excess level. However, the influences are not very noticeable as existing studies state that the influence is relatively small. For example, Vinha [15] found that the number of occupants has almost no influence on the average values of moisture excess and whether there are more or less than 3 occupants, the moisture content indoors will be increased by $1.9 \mathrm{~g} / \mathrm{m}^{3}$ on average during the cold period and $0.6 \mathrm{~g} / \mathrm{m}^{3}$ during the hot period in heavyweight singlefamily. Similar results are presented by Kalamees [12] in the case of buildings in Estonia and Finland. He concluded that in houses with more than 3 occupants the moisture increase is around $1.8 \mathrm{~g} / \mathrm{m}^{3}$ while fore less than 3 occupants around $1.7 \mathrm{~g} / \mathrm{m}^{3}$. Greater impact on moisture supply provides human density - according to a study [12], in buildings with $>35 \mathrm{~m}^{2} /$ person average moisture supply was $+1.3 \mathrm{~g} / \mathrm{m}^{3}$ with $10 \%$ critical value $+3.3 \mathrm{~g} / \mathrm{m}^{3}$ and for $\leq 35 /$ person $+1.7 \mathrm{~g} / \mathrm{m}^{3}$ in average with $10 \%$ critical value $+4.1 \mathrm{~g} / \mathrm{m}^{3}$ respectively. According to measurements [13] in historic wooden apartment buildings built before 1940 in Estonia with average occupant density $26 \mathrm{~m}^{2} /$ person, the diurnal moisture excess during the cold period was $+3.3 \mathrm{~g} / \mathrm{m}^{3}$ with $10 \%$ critical value $+5.1 \mathrm{~g} / \mathrm{m}^{3}$.

Another influencing factor is the type of ventilation system and ventilation air volumes. As expected the studies [5], [12] show that moisture supply was on average higher in more airtight houses and lower in leaky houses. In houses with natural ventilation, the average moisture level during the cold period was higher by $19 \%$ compared with mechanical ventilation $\left(+2.1 \mathrm{~g} / \mathrm{m}^{3}\right.$ compared with $\left.+1.7 \mathrm{~g} / \mathrm{m}^{3}\right)$. However, during summer in both studies moisture excess in houses with natural ventilation was twice than in houses with balanced ventilation $\left(+0.9 \mathrm{~g} / \mathrm{m}^{3}\right.$ to $+0.4 \mathrm{~g} / \mathrm{m}^{3}$ and $+1.4 \mathrm{~g} / \mathrm{m}^{3}$ to $+0.7 \mathrm{~g} / \mathrm{m}^{3}$ ). Moisture excess can also vary depending on the age of the house and type of ventilation system, giving higher values for old houses and houses with inefficient ventilation systems [9]. The influence of the ventilation system on energy consumption for various countries located by the Baltic sea has been shown in the existing study [16].

In all examined studies differences in moisture supply values between different houses were large (maximum value is several times bigger than the minimum), so it is not correct to use average values as a design value for hygrothermal calculations. Therefore, the International Energy Agency Annex 24 [17] has recommended the use of $10 \%$ critical level hygrothermal loads higher than their normative value should not appear in more than $10 \%$ of the cases.

The analysis of existing researches indicates that there is a necessity to perform humidity measurements for residential and office buildings to develop localization guidelines for the standard EN ISO 13788:2012.

\section{Methodology}

The field measurements were carried out in three apartments of multi-story residential buildings (low occupancy, 1-2 persons per apartment) and a landscape office. The occupancy for the apartments was 25, 27.5 and $29 \mathrm{~m}^{2} /$ person respectively while for the office it was varying as there were between two to six persons present. On average the working area for a person in the office could be estimated as $11 \mathrm{~m}^{2} /$ person. All measured buildings are located in Riga. The ventilation systems for the residential buildings were natural type without any mechanical exhausts while for the office building fully mechanical centralized ventilation system was operating. In the case of residential buildings, the window opening to ensure airing was also possible. The persons during the test time were instructed to act as close to everyday behaviour as possible, thus meaning that if they felt the necessity, they opened the windows to let the fresh air in.

For each measurement station, a survey was performed to be filled by the occupants for further data analysis. The survey involved questions regarding the building and its size, ventilation system, clothe drying specifics as well as showering and cooking habits.

The temperature and relative humidity were measured with five-minute intervals over several month 
periods in bedrooms, living rooms, landscape office and outdoors. The temperatures were logged through Extech SD800 loggers with measurement range and accuracy of $0{ }^{\circ} \mathrm{C}$ to $+50{ }^{\circ} \mathrm{C} \pm 0.8{ }^{\circ} \mathrm{C}$, humidity -10 to $90 \% \pm 4 \%$. The indoor loggers were located on an accessible shelf about $1.1-1.5 \mathrm{~m}$ height outside the proximity of a place where a person would be present for prolonged periods. The outdoor logger was located on a loggia and protected from direct solar radiation and driving rain, see Fig. 2.
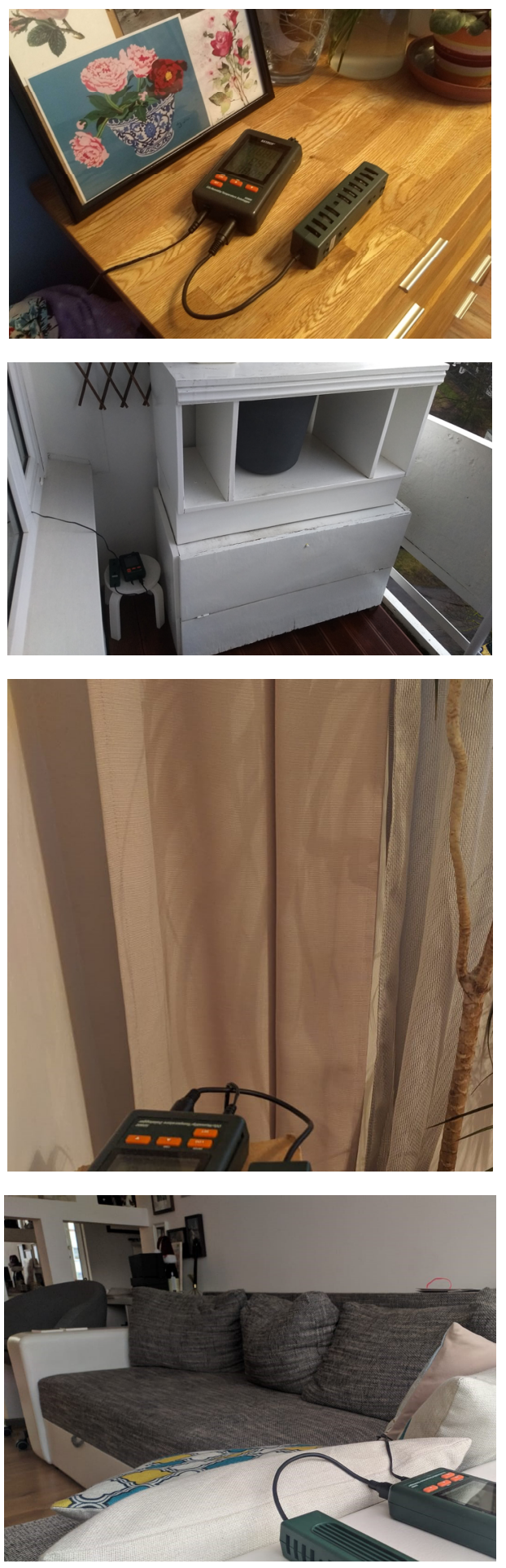

Fig. 2. Examples of measurement process for indoor and outdoor conditions
Based on temperature and RH measurements, the difference between indoor and outdoor air absolute humidity is calculated and the moisture excess $\Delta \mathrm{v}\left(\mathrm{g} / \mathrm{m}^{3}\right)$ is determined by the following equation:

$$
\Delta \mathrm{v}=\mathrm{v}_{\mathrm{i}}-\mathrm{ve}_{\mathrm{e}}
$$

where $v_{i}$ is the humidity by volume of indoor air $\left(\mathrm{g} / \mathrm{m}^{3}\right)$ and $\mathrm{v}_{\mathrm{e}}$ is the humidity by volume of outdoor air $\left(\mathrm{g} / \mathrm{m}^{3}\right)$.

From the five-minute interval data average moisture excess was calculated for each hour, so hourly moisture excess data is used in analyzing. To analyze the dependency of moisture excess on the outdoor climate and to eventually determine the critical moisture excess values, the data for each room was sorted separately according to the outdoor air temperature, using a $0.1{ }^{\circ} \mathrm{C}$ increment of the outdoor temperature. From these sorted values, maximum, minimum, mean and $10 \%$ critical levels (90\% percentile and $10 \%$ percentile) for each room and temperature were determined.

To decrease the $90 \%$ percentile moisture excess fluctuations caused by a limited amount of data for each temperature, an average $90 \%$ percentile for $1{ }^{\circ} \mathrm{C}$ step outdoor temperature was calculated.

\section{Results and discussion}

Measured data from outdoor logger was compared with data from "Latvian Environment, Geology and Meteorology Centre" database (meteo.lv), station "Rīga Universitāte" for the period of 20.11.2019-04.03.2020. The comparison is seen in Fig. 3 and Fig. 4.

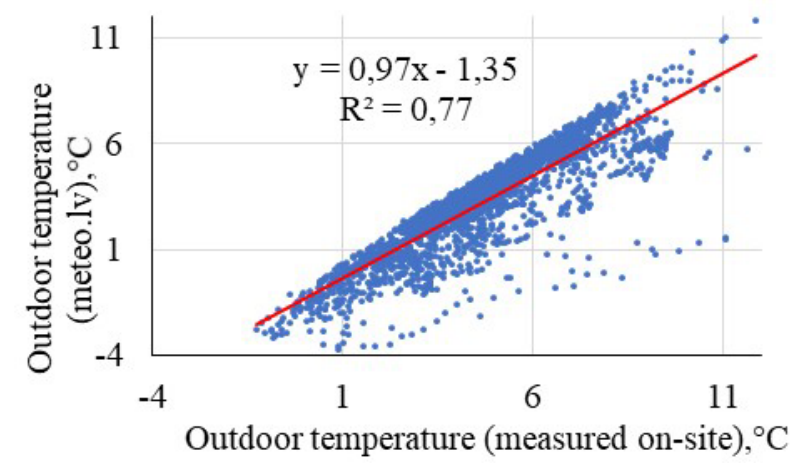

Fig. 3. Comparison of outdoor temperature measurements

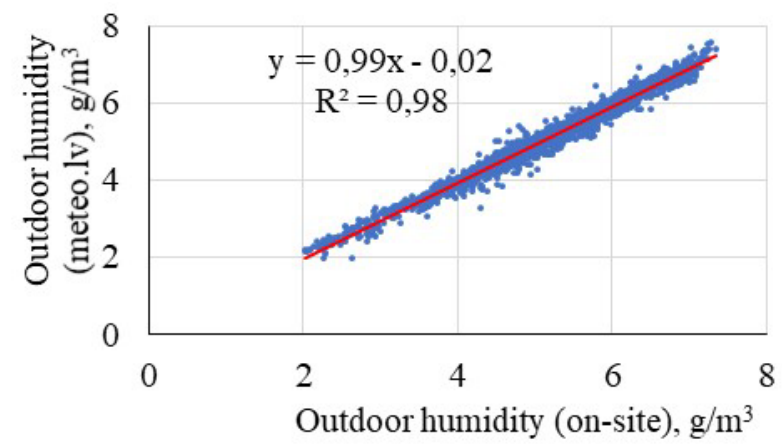

Fig. 4. Comparison of outdoor humidity measurements 
According to Fig. 3, outdoor temperatures, measured on-site, in average are higher than outdoor temperatures from the official meteo station, that can be explained by higher temperatures of surrounding surfaces and lower air exchange rate on the loggia that results in air stagnation and temperature increase around data logger comparing with outdoor air temperature outside the loggia. Therefore, the data from the "Latvian Environment, Geology and Meteorology Centre" database for the outdoor temperature and relative humidity are used in the further analysis. At the same time Fig. 4 shows that outdoor absolute humidity, calculated from on-site measured data, and data from meteo database is almost identical.

The preliminary results of the performed moisture excess measurements were compiled and statically analyzed. Fig. 5 shows the hourly moisture excess as dots for the apartment nr. 1 (with living area 25 $\mathrm{m}^{2} /$ person).

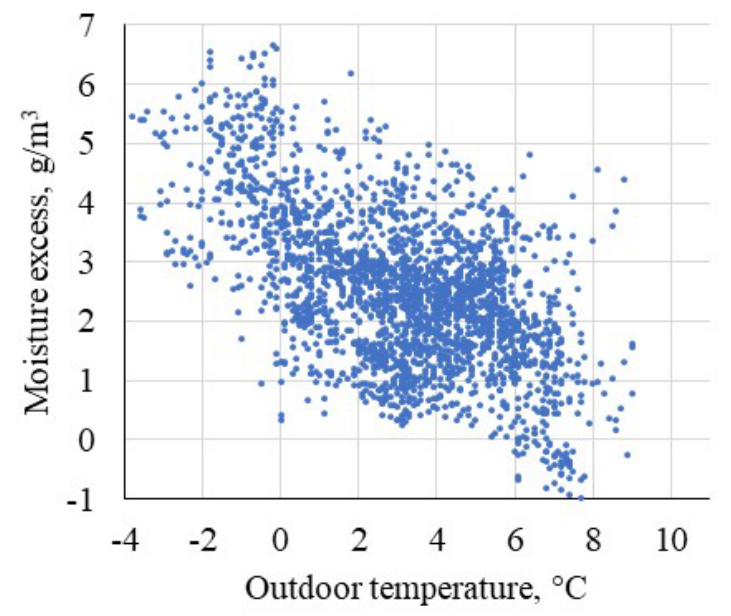

Fig. 5. Hourly moisture excess data for $1^{\text {st }}$ apartment

As can be seen from Fig. 5, it is hard to notice a direct relation between outdoor temperature and moisture excess. Although with increased outdoor temperature the density of measurement point scatter indicates of the moisture excess decrease each single measurement point can still strongly vary. Therefore the $90 \%$ percentile data filtering is applied.

In Fig. 6 the minimal, maximal, mean, as well as 10 and 90 percentiles of moisture excess between indoors and outdoors depending on outdoor temperature for a single apartment, are shown. The results indicate that on average the moisture excess decreases with the increase of outside temperature. If we consider the mean values than the moisture excess falls from around $4 \mathrm{~g} / \mathrm{m}^{3}$ at $0{ }^{\circ} \mathrm{C}$ to $1 \mathrm{~g} / \mathrm{m}^{3}$ at $+7{ }^{\circ} \mathrm{C}$ while for $90 \%$ percentile the decrease is from $5 \mathrm{~g} / \mathrm{m}^{3}$ to $2.4 \mathrm{~g} / \mathrm{m}^{3}$ at respective outside temperatures. At the same time, the graph shows that if we look at a specific residential apartment the actual moisture excess at any given point varies and does not form a linear decrease. This is dependent on the actions that are performed in the apartment. For example, the sudden increases in the moisture can be linked with the clothes drying process which took place in the specific room. As the length of measurements is still not very long these special instances are well visible in the graph. With the increase of measurement points, they will slowly smooth out as it is relatively unlikely that the cloth drying will be performed only at specific outside air conditions. It must be noted that the temperature range is only from $-3.8^{\circ} \mathrm{C}$ to $+9.6{ }^{\circ} \mathrm{C}$ due to the unnaturally warm winter. This also influences the validity of results regarding the top and bottom temperature range as there have been a smaller number of hours with such outdoor temperatures. The measurements are still ongoing to gather data regarding wider outdoor temperature range.

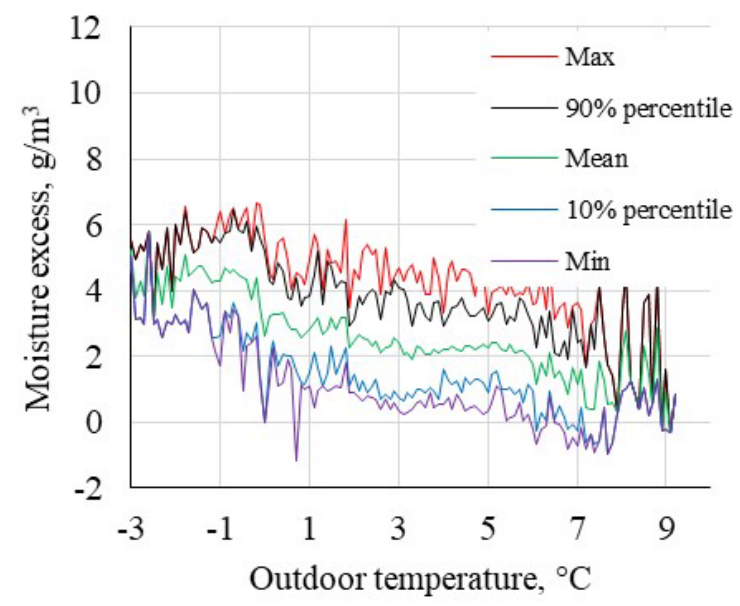

Fig. 6. Moisture excess in $1^{\text {st }}$ apartment

To compare the moisture excess for all three measured apartments Fig. 7 is generated.

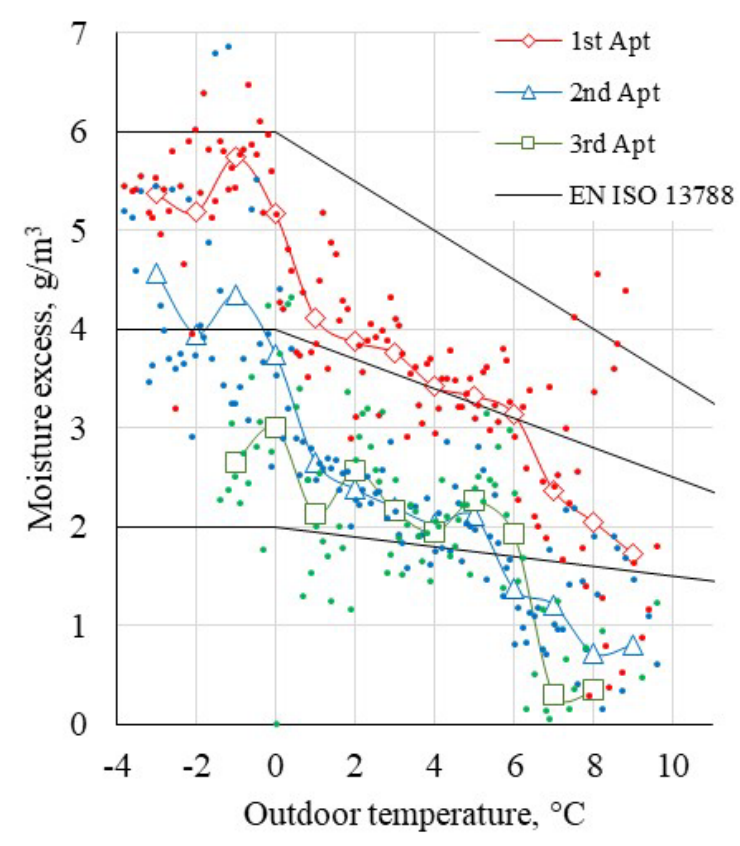

Fig. 7. 90\% percentile moisture excess in 3 apartments

The results show that there is a noticeable difference between the various objects although they follow a general trendline. The difference can be related to the fact that in the $1^{\text {st }}$ and $3^{\text {rd }}$ apartment the number of 
occupants was 2 , while in $2^{\text {nd }}$ only 1 . Also, only in the $1^{\text {st }}$ apartment, the clothes were dried in the same premise as the measurements were performed. The results show that for apartments Nr. 2 and Nr. 3 the moisture excess is below the threshold provided in standard EN ISO 13788:2012 for humidity class 2, which represents offices and dwellings with normal occupancy and ventilation. However, the $1^{\text {st }}$ apartment is slightly above and can be classified as class 3 - dwellings with low occupancy.

The results of the averaged moisture excess from the three apartments are shown in Fig. 8. The moisture excess is close to the stated values of class 2 from the standard EN ISO 13788. According to the information in the standard, the deflection point of the moisture supply curve (i.e. when it goes from a constant value to a linear decrease as temperature increases) should be at $0^{\circ} \mathrm{C}$ while the results of studies from Finland, Estonia and Norway indicate that this point should be at $+5^{\circ} \mathrm{C}$. At the same time, our study at a given moment does not back up this as there are no noticeable changes in the form of the graph depending on the outdoor temperature and the moisture excess does not reach a constant value in our measured outdoor temperature range. To further study this, more field measurements are necessary for a prolonged period.

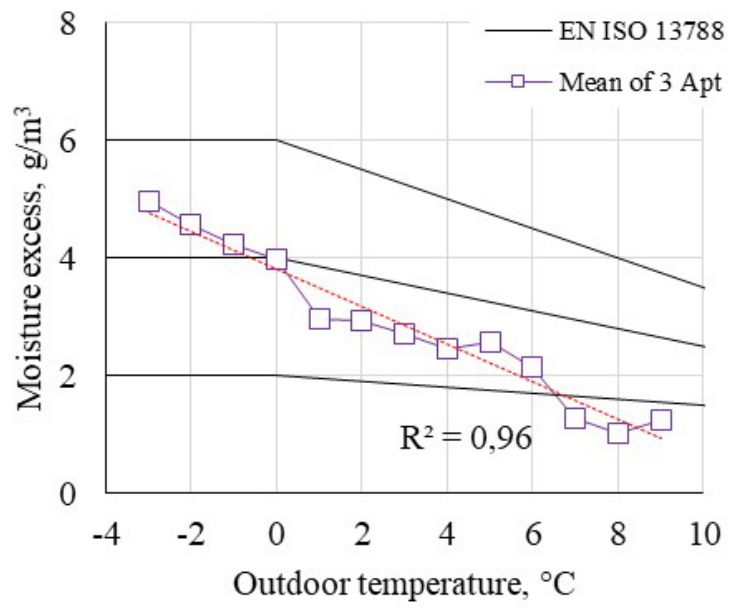

Fig. 8. Mean $90 \%$ percentile moisture excess of 3 apartments

The results of the measurement from the office are shown in Fig. 9. The graph shows that this landscape office for the greater period of measurements corresponds to the humidity class 1 according to EN ISO 13788, which is described as unoccupied building or storage of dry goods. This means that for the given office there are very low excess moisture values indicating a small amount of moisture load in the indoors. This could be explained by the fact that the occupancy density for the offices is low coupled with the constant working of the mechanical ventilation system.

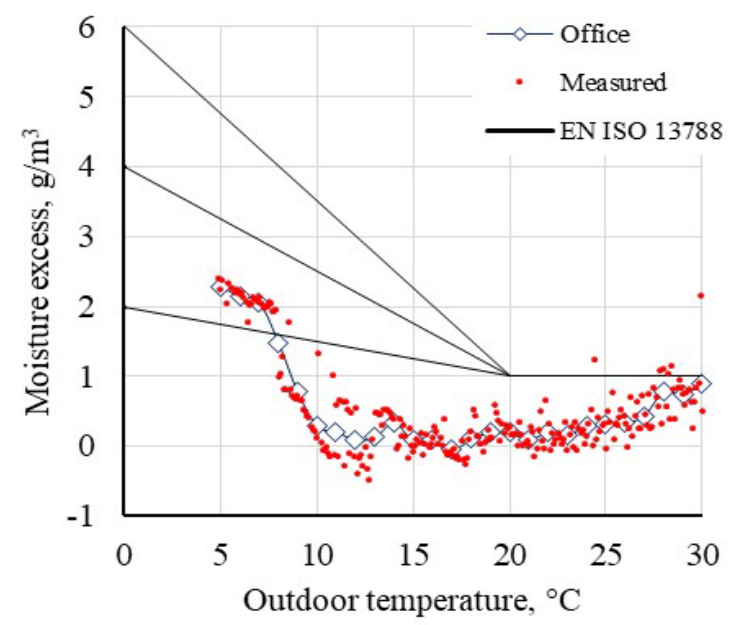

Fig. 9. 90\% percentile moisture excess of office

\section{Conclusions}

This paper presents the preliminary results of moisture excess measurements of three apartments and a single office building for a two-month period.

The results show that on average for apartments with low occupancy and no humidification the moisture excess of the $90 \%$ percentile level is above $+4.0 \mathrm{~g} / \mathrm{m}^{3}$ during the cold period and linearly decreases to $+0.6 \mathrm{~g} / \mathrm{m}^{3}$ at $+10^{\circ} \mathrm{C}$. This is somewhat different than stated in the standard EN ISO 13788 as the majority of the results of moisture excess fall in between 2 and 4 $\mathrm{g} / \mathrm{m}^{3}$. This would represent class 2 which is usually not used to describe residential buildings. The preliminary results do not indicate a deflection point of the moisture supply curve, which is mentioned both in from the standard EN ISO 13788 and previous studies.

The results of a single landscape office show that for the specific case the moisture excess is noticeably lower than expected and stated in the literature.

To obtain results with higher reliability and cover a wider range of outdoor temperatures it is planned to continue the measurements and perform them in more buildings.

\section{Acknowledgements}

This work has been supported by the European Regional Development Fund within the Activity 1.1.1.2 "Postdoctoral Research Aid" of the Specific Aid Objective 1.1.1 "To increase the research and innovative capacity of scientific institutions of Latvia and the ability to attract external financing, investing in human resources and infrastructure" of the Operational Programme "Growth and Employment" (No. 1.1.1.2/VIAA/1/16/033).

\section{References}

1. S. Dedesko and J. A. Siegel, Microbiome (2015)

2. C. G. Bornehag, J. Sundell, S. Bonini, A.

Custovic, P. Malmberg, S. Skerfving, T. 
Sigsgaard, and A. Verhoeff, Indoor Air (2004)

3. W. J. Fisk, Q. Lei-Gomez, and M. J. Mendell, Indoor Air (2007)

4. ISO - International Standard Organization, Build. Stand. Inst. (2012)

5. T. Kalamees, J. Vinha, and J. Kurnitski, J. Build. Phys. (2006)

6. S. Ilomets, T. Kalamees, and J. Vinha, J. Build. Phys. (2018)

7. L. Arena, P. Mantha, and A. N. Karagiozis, SSRN Electron. J. (2012)

8. H. Zhang and H. Yoshino, Build. Environ. (2010)

9. S. Geving and J. Holme, J. Build. Phys. (2012)

10. N. Tolstoy, in Indoor Air' 93 (Helsinki, 1993), p. 6

11. T. Kalamees, J. Kurnitski, J. Vinha, and L. Tech, in 7th Symp. Build. Phys. Nord. Ctries. (Iceland, 2005), pp. 13-15

12. T. Kalamees, Indoor Built Environ. (2006)

13. E. Arumägi, T. Kalamees, and U. Kallavus, Proc. Est. Acad. Sci. 64, 146 (2015)

14. J. Zemitis, A. Borodinecs, and M. Frolova, Energy Build. (2016)

15. J. Vinha, M. Salminen, K. Salminen, T. Kalamees, J. Kurnitski, and M. Kiviste, J. Build. Phys. 42, 239 (2018)

16. D. Baranova, D. Sovetnikov, and A. Borodinecs, Sci. Technol. Built Environ. (2018)

17. C. Sanders, Heat, Air and Moisture Transfer in Highly Insulated Building Envelopes (HAMTIE): Report, Volume 2, Task 2: Environmental Conditions (Belgium, 1996) 